\title{
A novel homozygous SLC19A2 mutation in a Portuguese patient with diabetes mellitus and thiamine-responsive megaloblastic anaemia
}

\author{
Sophia Tahir ${ }^{1 \dagger}$, Lieve GJ Leijssen ${ }^{1 \dagger}$, Maha Sherif ${ }^{1}$, Carla Pereira ${ }^{2}$, Anabela Morais ${ }^{3}$ and Khalid Hussain ${ }^{1,4^{*}}$
}

\begin{abstract}
Thiamine-responsive megaloblastic anaemia (TRMA) is a rare syndrome where patients present with early onset diabetes mellitus, megaloblastic anaemia and sensorineural deafness. This report describes a new case of TRMA syndrome in a female patient of Portuguese descent, born to unrelated parents. The patient was found to have a novel homozygous change R397X in exon 4 of the SLC19A2 gene, leading to a premature stop codon. The patient's diabetes and anaemia showed a good response to daily thiamine doses, reducing the daily insulin dose requirement. The report further indicates that TRMA is not only limited to consanguineous or ethnically isolated families, and should be considered as a differential diagnosis for patients presenting with suggestive clinical symptoms.
\end{abstract}

Keywords: TRMA, Diabetes mellitus, Sensorineural deafness, Megaloblastic anaemia, SLC19A2 mutation

\section{Introduction}

Thiamine-responsive megaloblastic anaemia (TRMA; OMIM 249270), also called Roger's syndrome, is a very rare autosomal recessive disorder characterized by early onset diabetes mellitus (DM), megaloblastic anaemia and sensorineural deafness. The syndrome was first described by Rogers et al. [1]. Other reported clinical findings in addition to the characteristic triad include congenital heart disease, arrhythmias, retinal degeneration, optic atrophy, aminoaciduria, short stature, situs inversus, Polycystic Ovarian Syndrome and stroke [2]. The disease can manifest anytime between infancy and adolescence, although often not all of the cardinal findings are manifested at onset. The variable phenotypic presentation of TRMA syndrome may cause a significant delay between the onset of symptoms and an accurate diagnosis. Treatment is symptomatic and includes pharmacological doses of thiamine (vitamin B1), which usually corrects hematological and

\footnotetext{
*Correspondence: khalid.hussain@ucl.ac.uk

${ }^{\dagger}$ Equal contributors

'Developmental Endocrinology Research Group, Clinical and Molecular Genetics Unit, Institute of Child Health, University College London, 30 Guilford Street, London WC1N 1EH, UK

${ }^{4}$ Department of Paediatric Endocrinology, Great Ormond Street Hospital for Children, NHS Foundation Trust, WC1N 3JH London, United Kingdom

Full list of author information is available at the end of the article
}

endocrine function, but neurological manifestations do not respond as well $[1,3]$.

Most of the TRMA patients originated from consanguineous families, which is consistent with autosomal recessive inheritance [4]. TRMA is caused by homozygous mutations in the SLC19A2 gene [4], which encodes a highaffinity thiamine transporter 1 protein (THTR-1) [5,6], located on chromosome 1q23.3. The human TRMA gene contains six exons that encode a protein of 497 amino acids with 12 transmembrane domains [7]. SLC19A2 is expressed in a wide range of human tissues including bone marrow, liver, colon, small intestine, pancreas, brain, retina, heart, skeletal muscle, kidney, lung, placenta, lymphocytes and fibroblasts [8].

To date, TRMA syndrome has been reported in around 30 families worldwide. Its prevalence and incidence are unknown. At least 43 mutations in the SLC19A2 gene have been found to cause TRMA. Most of these mutations lead to the production of an abnormally short, nonfunctional THTR-1. Other mutations change single protein building blocks (amino acids) in THTR-1, which disrupts the proper folding of the protein or prevents it from reaching the cell surface. All of these mutations prevent THTR-1 from bringing thiamine into the cell. 
Here we report a female patient with TRMA, belonging to a non-consanguineous family of Portuguese descent. A novel homozygous mutation was found in the SLC19A2 gene leading to a premature stop codon. The patient presented with the typical features TRMA, diabetes mellitus, sensorineural deafness and megaloblastic anaemia.

\section{Case presentation}

A girl, 14 months of age, was born at full term, birth weight $3.03 \mathrm{~kg}$ after an uneventful pregnancy and delivery to non-consanguineous parents of Portuguese descent. Her mother is known with thalassemia minor, her father is healthy. A second degree paternal cousin is known with DM type 1 , diagnosed at the age of 31 years.

At the age of 10 months, our patient was referred to the hospital because of fever of unknown origin. At that time, she was found to have hyperglycaemia of $509 \mathrm{mg} / \mathrm{dl}$ [28 mmol/L] and diabetic ketoacidosis $\left(\mathrm{pH} \mathrm{7.26,} \mathrm{HCO}_{3}\right.$ 10.9, serum and urine ketones ++$)$. Other laboratory evaluation revealed anaemia $(\mathrm{Hb} 8.3 \mathrm{~g} / \mathrm{dl})$ and high CRP (17.1 mg/dl). Cardiovascular examination showed an I/VI systolic heart murmur and she presented with skin pallor. Although treatment with insulin was started according to the diabetic ketoacidosis protocol, there was progressive $\mathrm{Hb}$ lowering (6.5 g/dl on day 10), a reticulocyte count of $54 \%$, low neutrophil (600 with WBC $10.700 / \mathrm{mm}^{3}$ ) and low platelets $\left(29000 / \mathrm{mm}^{3}\right)$. For this, she was treated with a blood transfusion at that time.

In the following months there was still progressive $\mathrm{Hb}$ lowering, maintaining MCV (81-87 fL), leukocytes between 7500 and 11900 with neutrophils $<3000$ and platelets went down to $67000 / \mathrm{mm}^{3}$. In addition, she needed another transfusion during febrile illness, due to CMV infection.

At 13 months of age she had ENT evaluation and hearing evoked potentials were made, confirming sensorineural deafness, which is treated with hearing prosthesis. In the meantime, she needed progressive growing doses of insulin (at 14 months $0.75 \mathrm{U} / \mathrm{kg}$ ).

After institution of thiamine supplementation $(75 \mathrm{mg} /$ day) and another blood transfusion, due to a rhinopharyngitis ( $\mathrm{Hb} 6.4 \mathrm{~g} / \mathrm{dl}$ and platelets $\left.101000 / \mathrm{mm}^{3}\right)$, the haemoglobin (present: 11.5-12.9 g/dl) and WBC (present: $12000-14000 / \mathrm{mm}^{3}$ with neutrophils $4.200-4.680 / \mathrm{microlL}$, platelets $>500000 / \mathrm{mm} 3$ ) increased. In addition, the patient's blood glucose showed an improvement (HbA1c: $6.5 \%, 47.5 \mathrm{mmol} / \mathrm{mol}$ ) and her daily insulin requirements progressively decreased to a $2 \mathrm{U} /$ day $(0.15 \mathrm{U} / \mathrm{kg} /$ day $)$.

Considering the clinical history of the patient, mutational analysis of the SLC19A2 gene was conducted. Primers were designed to cover all six exons and their flanking intronic regions using the online Primer 3 software [9]. The sequencing reaction was conducted using the BigDye Terminator V1.1 Cycle Sequencing kit (Applied BioSystems, Foster City, CA, USA). The patient was found to be homozygous for the c.1189A $>\mathrm{T}$ nucleotide change (protein change R397X) in exon 4 of the SLC19A2 gene. This mutation was absent from dbSNP database [10], 1000 Genomes Project [11] and in Exome Variant Server [12] in the homozygous state. The mutation leads to stop codon and causes an early protein truncation and was predicted to be deleterious by the online PROVEAN PROTEIN software [13]. The c.1189A $>\mathrm{T}$ change is previously reported (SNP ID: rs371383730) in the heterozygous state in a single European-American individual on the Exome Variant Server [12]. The parents of the patient were also found to be heterozygous carriers for the mutation, which was absent in the control (Figure 1).

\section{Discussion}

The first case of TRMA syndrome was described in 1969 by Rogers et al. [1]. Most of the early cases which followed have been in patients from a Middle Eastern or Asian background. However a growing number of cases recently report patients from non-consanguineous European backgrounds $[2,14,15]$. Here we report a female patient from a non-consanguineous Portuguese family with a homozygous nonsense mutation in the SLC19A2 gene.

Thiamine plays an essential role in carbohydrate metabolism and energy production reactions. Under physiological

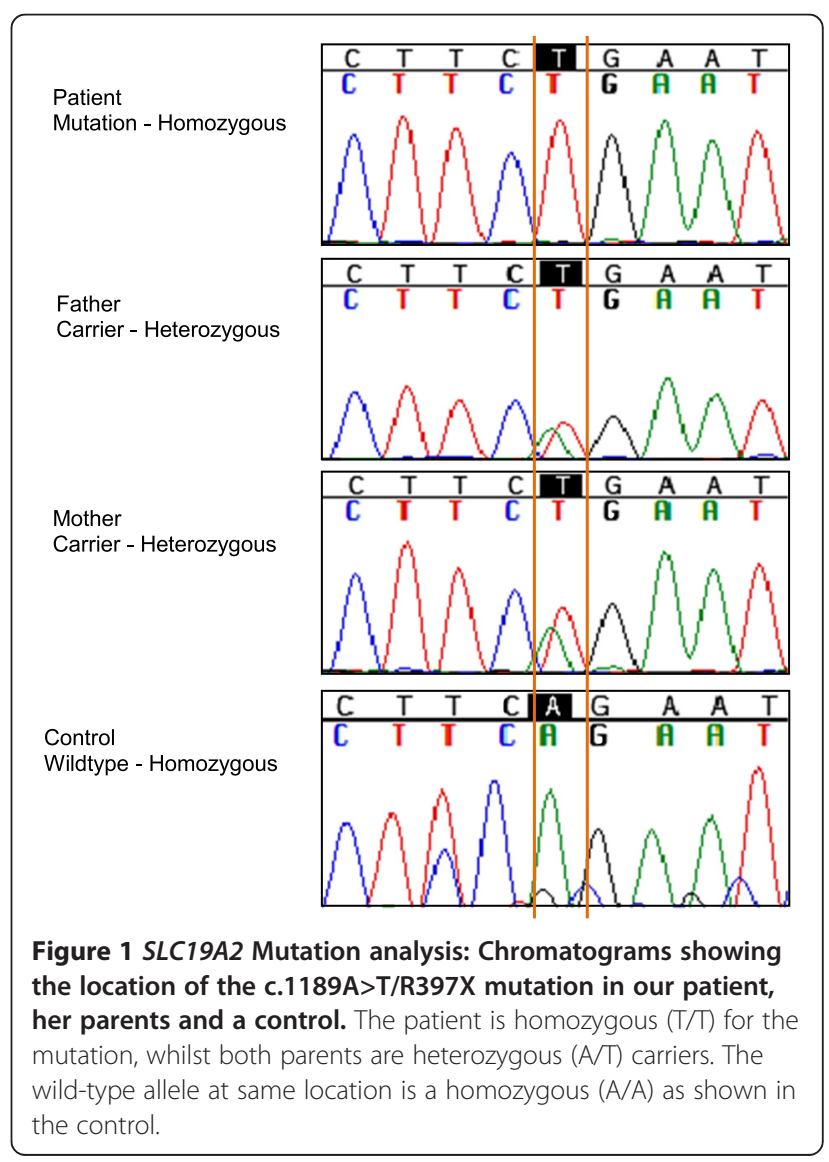


concentrations of thiamine as obtained from normal diet, it is transported by two high affinity carriers found in the intestine - THTR-1 encoded by the SLC19A2 gene, and THTR-2 encoded by the SLC19A3 gene. Both genes are expressed in most body tissues; however the cochlear inner hair cells, pancreatic islet cells and erythropoietic precursor cells only express SLC19A2. Under high thiamine concentrations, thiamine crosses the cell membrane through passive diffusion [8,16-18]. In TRMA syndrome the active uptake of thiamine by carrier mediated mechanisms is disrupted leading to thiamine deficiency. As most cells have a compensatory mechanism via THTR-2, only the three THTR-1 dependent cells are the most affected by thiamine deficiency, and thus explain the clinical triad associated with TRMA syndrome [19].

The high level of thiamine in pancreas is essential for its normal endocrine and exocrine function [20]. Thiamine deficiency negatively impacts insulin regulation, as the pancreatic islet cells from thiamine deficient rats show impaired insulin secretion [21]. This is possibly due to cell death and apoptosis [22].

Thiamine is essential for normal auditory development and function, and infants fed thiamine deficient meals develop auditory problems [23]. The higher expression of THTR-1 in the cochlear inner hair cells than the outer hair cells suggests its essential role for inner hair cell function [24]. Slc19a2 null mice show selective loss of inner hair cells, within 1-2 weeks of being subjected to thiamine deficient diet [25].

To date 43 mutations have been described in the SLC19A2 gene (HGMD January 2015) [26]. Majority are missense and nonsense changes, followed by small insertions and deletions. A large intragenic deletion was also reported by Beshlawi et al., where a 5224 base pair region in SLC19A2 was deleted in 6 patients [27]. Cases reporting compound heterozygosity show that TRMA is not only limited to consanguineous or ethnically isolated families $[2,14,15]$.

Most TRMA patients show the cardinal findings of the syndrome; however the onset of the different symptoms may vary [2]. Our patient developed all 3 symptoms between 10 to 13 months of age. Furthermore the observation of other clinical symptoms in TRMA apart from the clinical triad makes it difficult to define a clear genotype-phenotype relationship. Visual impairments, cardiac anomalies and neurological impairments are seen in some patient with TRMA and not others, despite carrying the same causative mutation [28-30].

Treatment with high thiamine doses produces a variable response in patients [31]. Usually this corrects for haematological and endocrinal findings, normalizing patient's anaemia and hyperglycaemia overtime. However patients have been reported where insulin therapy was still required [31]. Thiamine supplementation becomes ineffective once the patient reaches puberty; follow up studies report patients requiring insulin therapy and regular blood transfusion during adulthood [7]. Low thiamine concentrations may cause cell death by apoptosis in TRMA patient fibroblast cells [22]. This may therefore lead to a reduced reserve of pancreatic beta cells, and as suggested by Valerio and colleagues, may be insufficient to meet the changing physiological demands of insulin during puberty [32]. Our patient required progressively increasing doses of insulin to control her blood glucose levels prior to TRMA diagnosis. This was reduced to a single dose of $2 \mathrm{U} /$ day $(0.15 \mathrm{U} / \mathrm{kg} /$ day) of insulin within 6 months of beginning on a thiamine dose of $75 \mathrm{mg} /$ day.

Hearing loss in SLC19A2 knockout mice can be reversed when fed with a high thiamine diet following a thiamine free diet [33]. However in humans the effect of thiamine deficiency seems to be irreversible for hearing loss [31]. One TRMA patient diagnosed without the development of hearing loss at one month of age, was started on early thiamine therapy, and still had no signs of hearing loss in the follow up period at 30 months of age [34]. Early intervention in this case could have occurred before the damage of thiamine deficiency affected hearing. It may still be possible that the patient goes on to develop hearing loss later in life. Patients with compound heterozygote mutations are reported to have a milder phenotype, with less severe hearing loss [2].

\section{Conclusion}

In summary we report a new case of TRMA syndrome in a patient from a non-consanguineous European family of Portuguese descent. The causative mutation, c.1189A $>$ T/ R397X is a novel nonsense mutation, introducing a premature stop codon in exon 4 for the SLC19A2 gene. Increasing number of cases are reported in European non consanguineous families, and therefore despite being rare, TRMA should be considered as a differential diagnosis in patients presenting with suggestive clinical symptoms. The patients generally respond well to thiamine supplementation, which keeps the condition under control - although only temporarily till the patient reaches puberty.

\section{Consent}

Written informed consent was obtained from the patient for publication of this Case report and any accompanying images. A copy of the written consent is available for review by the Editor-in-Chief of this journal.

\section{Abbreviations}

DM: Diabetes mellitus; TRMA: Thiamine responsive megaloblastic anaemia; THTR-1: High-affinity thiamine transporter 1 protein; THTR-2: High-affinity thiamine transporter 2 protein; SLC19A2: Solute carrier family 19 (thiamine transporter), member 2; SLC19A3: Solute carrier family 19 (thiamine

transporter), member 3 . 


\section{Competing interests}

The authors declare that they have no competing interests.

\section{Authors' contributions}

ST, LL and MS conducted the genetic analysis on the patient. ST and LL drafted the original manuscript. CP and AM took part in the clinical care of the patient and $\mathrm{KH}$ reviewed and edited the manuscript. All authors have read and approved the final version of the manuscript submitted.

\section{Acknowledgement}

We would like to thank Dr Lurdes Sampaio for providing us with an up to date clinical report of the patient.

\section{Author details}

${ }^{1}$ Developmental Endocrinology Research Group, Clinical and Molecular Genetics Unit, Institute of Child Health, University College London, 30 Guilford Street, London WC1N 1EH, UK. Endocrinology Unit, Department of Paediatrics, Hospital de Santa Maria - CHLN, Lisbon, Portugal. ${ }^{3}$ Hematology Unit, Department of Paediatrics, Hospital de Santa Maria - CHLN, Lisbon, Portugal. ${ }^{4}$ Department of Paediatric Endocrinology, Great Ormond Street Hospital for Children, NHS Foundation Trust, WC1N 3JH London, United Kingdom.

Received: 13 November 2014 Accepted: 19 January 2015

\section{Published online: 15 April 2015}

\section{References}

1. Porter FS, Rogers LE, Sidbury Jr JB. Thiamine-responsive megaloblastic anemia. J Pediatr. 1969;74:494-504.

2. Bergmann AK, Sahai I, Falcone JF, Fleming J, Bagg A, Borgna-Pignati C, et al. Thiamine-responsive megaloblastic anemia: identification of novel compound heterozygotes and mutation update. J Pediatr. 2009;155(6):888-92.

3. Alzahrani AS, Baitei E, Zou M, Shi Y. Thiamine transporter mutation: an example of monogenic diabetes mellitus. Eur J Endocrinol. 2006;155(6):787-92.

4. Neufeld EJ, Mandel H, Raz T, Szargel R, Yandava CN, Stagg A, et al. Localization of the gene for thiamine-responsive megaloblastic anemia syndrome, on the long arm of chromosome 1, by homozygosity mapping. Am J Hum Genet. 1997;61(6):1335-41.

5. Labay $\mathrm{V}$, Raz T, Baron D, Mandel H, Williams $H$, Barrett $T$, et al. Mutations in SLC19A2 cause thiamine-responsive megaloblastic anaemia associated with diabetes mellitus and deafness. Nature Genet. 1999;22(3):300-4.

6. Dutta B, Huang W, Molero M, Kekuda R, Leibach FH, Devoe LD, et al. Cloning of the human thiamine transporter, a member of the folate transporter family. J Biol Chem. 1999;274(45):31925-9.

7. Ricketts CJ, Minton JA, Samuel J, Ariyawansa I, Wales JK, Lo IF, et al. Thiamine-responsive megaloblastic anaemia syndrome: long-term follow-up and mutation analysis of seven families. Acta Paediatr. 2006;95(1):99-104

8. Fleming JC, Tartaglini E, Steinkamp MP, Schorderet DF, Cohen N, Neufeld EJ. The gene mutated in thiamine responsive anemia with diabetes and deafness (TRMA) encodes a functional thiamine transporter. Nat Genet. 1999:22(3):305-8

9. Department of Bioinformatics. Program for designing PCR primers and oligos. Available at: http://bioinfo.ut.ee/primer3.

10. National Center for Biotechnology Information. Search for Short Genetic Variations. Available at: http://www.ncbi.nlm.nih.gov/projects/SNP/.

11. The 1000 Genomes Project. A deep catalog of human genetic variation. Available at: http://www.1000genomes.org.

12. National Heart, Lung and Blood Institute. NHLBI Grand Opportunity Exome Sequencing Project, to discover novel mutations and mechanisms contributing to heart, lung and blood disorders. Available at: http://evs.gs. washington.edu/EVS/.

13. Choi Y, Sims GE, Murphy S, Miller JR, Chan AP. Predicting the functional effect of amino acid substitutions and indels. PLoS ONE. 2012;7(10):e46688 Available at http://provean.jcvi.org/index.php.

14. Mozzillo E, Melis D, Falco M, Fattorusso V, Taurisano R, Flanagan SE, et al. Thiamine responsive megaloblastic anemia: a novel SLC19A2 compound heterozygous mutation in two siblings. Pediatric Diabetes. 2013;14:384-7.

15. Pichler H, Zeitlhofer P, Dworzak MN, Diakos C, Haas OA, Kager L. Thiamine-responsive megaloblastic anemia (TRMA) in an Austrian boy with compound heterozygous SLC19A2mutations. Eur J Pediatr. 2012;171:1711-5.
16. Rindi G, Ferrari G. Thiamine transport by human intestine in vitro. Experientia. 1977;33(2):211-3.

17. Laforenza U, Patrini C, Alvisi C, Faelli A, Licandro A, Rindi G. Thiamine uptake in human intestinal biopsy specimens, including observations from a patient with acute thiamine deficiency. Am J Clin Nutr. 1997;66(2):320-6.

18. Hoyumpa Jr AM, Strickland R, Sheehan JJ, Yarborough G, Nichols S. Dual system of intestinal thiamine transport in humans. J Lab Clin Med. 1982:99(5):701-8.

19. Reidling JC, Lambrecht N, Kassir M, Said HM. Impaired intestinal vitamin B1 (thiamin) uptake in thiamin transporter-2-deficient mice. Gastroenterology. 2010;138(5):1802-9.

20. Prasannan KG, Sundaresan R, Venkatesan K. Thiamine deficiency and protein secretion by pancreatic slices in vitro. Experientia. 1997;33:169-70.

21. Rathanaswami P, Pourany A, Sundaresan R. Effects of thiamine deficiency on the secretion of insulin and the metabolism of glucose in isolated rat pancreatic islets. Biochem Int. 1991;25(3):577-83.

22. Stagg AR, Fleming JC, Baker MA, Sakamoto M, Cohen N, Neufeld EJ. Defective high affinity thiamine transporter leads to cell death in thiamineresponsive megaloblastic anemiasy ndrome fibroblasts. J Clin Invest. 1999;103(5):723-9.

23. Attias J, Raveh E, Aizer-Dannon A, Bloch-Mimouni A, Fattal-Valevski A. Auditory system dysfunction due to infantile thiamine deficiency: long-term auditory sequelae. Audiol Neurootol. 2012;17(5):309-20.

24. Fleming JC, Steinkamp MP, Kawatsuji R, Tartaglini E, Pinkus JL, Pinkus GS, et al. Characterization of a murine high-affinity thiamine transporter, SIC19a2. Mol Genet Metab. 2001;74:273-80.

25. Liberman MC, Tartaglini E, Fleming JC, Neufeld EJ. Deletion of SLC19A2, the high affinity thiamine transporter, causes selective inner hair cell loss and an auditory neuropathy phenotype. J Assoc Res Otolaryngol. 2006;7(3):211-7.

26. Stenson PD, Ball EV, Mort M, Phillips AD, Shiel JA, Thomas NS, et al. Human Gene Mutation Database (HGMD): 2003 update. Hum Mutat. 2003;21(6):577-81.

27. Beshlawi I, Al Zadjali S, Bashir W, Elshinawy M, Alrawas A, Wali Y. Thiamine responsive megaloblastic anemia: the puzzling phenotype. Pediatr Blood Cancer. 2014;61(3):528-31.

28. Akbari MT, Zare Karizi S, Mirfakhraie R, Keikhaei B. Thiamine-responsive megaloblastic anemia syndrome with Ebstein anomaly: a case report. Eur J Pediatr. 2014:173(12):1663-5.

29. Ozdemir MA, Akcakus M, Kurtoglu S, Gunes T, Torun YA. TRMA syndrome (thiamine-responsive megaloblastic anemia): a case report and review of the literature. Pediatr Diabetes. 2002;3(4):205-9.

30. Setoodeh A, Haghighi A, Saleh-Gohari N, Ellard S, Haghighi A. Identification of a SLC19A2 nonsense mutation in Persian families with thiamine-responsive megaloblastic anemia. Gene. 2013;519(2):295-7.

31. Ghaemi N, Ghahraman M, Abbaszadegan MR, Baradaran-Heravi A, Vakili R. Novel mutation in the SLC19A2 gene in an Iranian family with thiamine-responsive megaloblastic anemia: a series of three cases. J Clin Res Pediatr Endocrinol. 2013;5(3):199-201.

32. Valerio G, Franzese A, Poggi $V$, Tenore A. A long-term follow-up of diabetes in two patients with thiamine-responsive megaloblastic anemia syndrome. Diabetes Care. 1998;21(1):38-41.

33. Oishi K, Hofmann S, Diaz GA, Brown T, Manwani D, Ng L, et al. Targeted disruption of SIC19a2, the gene encoding the high-affinity thiamin transporter Thtr-1, causes diabetes mellitus, sensorineural deafness and megaloblastosis in mice. Hum Mol Genet. 2002;11(23):2951-60.

34. Onal H, Bariş S, Ozdil M, Yeşil G, Altun G, Ozyilmaz I, et al. Thiamine-responsive megaloblastic anemia: early diagnosis may be effective in preventing deafness. Turk J Pediatr. 2009:51(3):301-4. 